\title{
APPLICATIONS OF DIFFERENTIAL CALCULUS IN ECONOMICS. A FEW SIMPLE EXAMPLES FOR FIRST-YEAR STUDENTS
}

\author{
Marek Biernacki
}

\begin{abstract}
First-year students usually ask whether they really need mathematics. This paper presents several simple examples applying differential calculus in microeconomics, which allow students to perceive that learning mathematics during their studies of economics does “pay off”.
\end{abstract}

Keywords: derivative of function of one variable and two variables, utility, elasticity.

Jel Classification: C20.

DOI: $10.15611 / \mathrm{dm} .2016 .13 .01$.

\section{Introduction}

First-year students of economics today include more and more opponents of mathematics who believe that mathematics is irrelevant for studying economics, hence they devote little effort and time to understand it. For this reason my lectures for first-year students demonstrate many applications of mathematics in economics in the hope to incentivize them to devote more effort and time to learning mathematics. My lectures in mathematics deal with microeconomics and macroeconomics. I try to make it obvious to my students that the mathematical approach to economics can claim to many advantages, including [Chiang 1994]:

1. The language of mathematics is concise and precise.

2. There exists a wealth of mathematical theorems at our service.

3. If we state explicitly all assumptions as a prerequisite to using mathematical theorems in economics, it keeps us from the minefield of erroneous conclusions.

4. It allows us to treat the general $n$-variable case.

\section{Marek Biernacki}

Department of Mathematics and Cybernetics, Wrocław University of Economics

marek.biernacki@ue.wroc.pl 
Professor Żylicz encourages us to approach lectures in mathematics in this way: "Even though the main purpose of teaching mathematics is training young minds, one cannot escape from the fact that a typical student expects to see a direct use of what he or she is learning. Hence mathematics courses have to take into account the specific requirements and traditions of a given discipline. Otherwise the students will revolt" [Żylicz 2006].

This paper is a sequel of my previous article on the applications of intervals in economics [Biernacki 2010]. The examples presented here should help introduce a derivative and related theorems.

\section{Economic interpretation of the derivative of one variable - marginality}

The derivative of a function $y=f(x)$ at point $a$, denoted by $f^{\prime}(a)$, equals the limit of the difference quotient (if it exist):

$$
f^{\prime}(a)=\lim _{h \rightarrow 0} \frac{f(a+h)-f(a)}{h} .
$$

The quotient on the right-side equals the slope of a secant line passing through the points $\mathrm{A}(a, f(a))$ and $\mathrm{B}(a+h, f(a+h))$. As $h$ approaches zero, the point $\mathrm{B}$ moves along the graph of $f$ to the point $\mathrm{A}$ and the left-side yields the slope of the tangent line (provided that the limit exists, i.e. when $f$ is smooth on an open interval containing A). When the function is differentiable at point $a$ (it has a derivative at $a$ ), then for small $h$ the slope of the secant line is approximately equal to the slope of the tangent line which indicates the rate of change of $f$ at point $a$, i.e.

$$
f^{\prime}(a) \approx \frac{f(a+h)-f(a)}{h} .
$$

Let us begin with the average cost of large-scale production. Total costs given the volume of output is a function of fixed costs, independent of the level of production $q$, and variable costs, volume-related. Thus we have: $C(q)=k+v(q)$.

The average cost of producing the volume $q$ is equal to:

$$
A C=\frac{k}{q}+\frac{v(q)}{q} .
$$


It is worth noticing during the class on the subject of the limit of function at a point that, given large volumes of output, the average cost depends on the quotient of variable costs and output:

$$
\lim _{q \rightarrow \infty} A C=\lim _{q \rightarrow \infty}\left(\frac{k}{q}+\frac{v(q)}{q}\right)=\lim _{q \rightarrow \infty} \frac{v(q)}{q} .
$$

Next we consider profitability of production. Let us assume that given the volume $q$ of production, we plan to increase output by $h$. The average cost of additional output $h$ is equal to:

$$
A(h)=\frac{C(q+h)-C(q)}{h} .
$$

If we compare it to the market price, we can test the profitability of our decision. Assume the company has a quadratic cost function $C(q)=0.001 q^{2}+2 q+1500$ with output level at 1000 and market price $p=5$. We get $C(1000)=4500$ and $A C=4.5$ which means that production is profitable. Let us now test the increase of production by $h$.

$$
A(h)=\frac{0.001(1000+h)^{2}+2(1000+h)+1500-4500}{h}=4+0.001 h
$$

is smaller than 5 for $h<1000$, hence at current market prices we can increase output and profit significantly.

As $h$ approaches zero (another exercise regarding the idea of a limit), we get the average cost of the added output, which can be interpreted as the cost of producing an additional unit of output given the current quantity $q$ (cf. formula 2). This limit is precisely the derivative $C^{\prime}(q)$ that is called the marginal cost with respect to $q$ (cf. formula 1 ):

$$
C^{\prime}(q)=\lim _{h \rightarrow 0} \frac{C(q+h)-C(q)}{h} .
$$

With our cost function $C^{\prime}(q)=0,002 q+2$ we get $C^{\prime}(1000)=4$, thus the cost of producing an additional unit of output given the current quantity $q$ equals 4 . 


\section{Examples of applications of derivatives in economics}

The first example deals with studying the influence of the increased sales price on profit by differentiating the product of functions. The revenue from sales of output equals the product of quantity and price, with quantity of sales being dependent on price: $R(p)=q(p) p$. Then in order to find out where the revenue is an increasing function of price, we differentiate the revenue function and see where the derivative is greater than zero:

$$
\frac{d R}{d p}=\frac{d q}{d p} p+q>0 \quad \text { which is equivalent to }-\frac{p}{q} \frac{d q}{d p}<1 .
$$

Since the demand is a decreasing function of the price, the left-side of this inequality, called the price elasticity of demand and denoted by $E(p)$, is a positive number. A small elasticity, less than 1, indicates an inelastic demand, i.e. profit decreases as price increases. The price elasticity of demand can be written as:

$$
E(p)=-\frac{q^{\prime}(p)}{q(p)} p=-\frac{\frac{d q}{q}}{\frac{d p}{p}} \approx-\frac{\frac{\Delta q}{q}}{\frac{\Delta p}{p}} .
$$

Let us note that along with a relative increase of the price, the demand will decrease by:

$$
-\frac{\Delta q}{q}=E(p) \frac{\Delta p}{p} .
$$

Let $q(p)=120-2 p$, then $E(p)=\frac{2}{q(p)} p$. Table 1 presents the changes in values taken by the variables of interest as a result of changes in the price, assuming given demand function.

Table 1. Relationship between revenue from sales and price

\begin{tabular}{|l|c|c|c|c|c|}
\hline Price $(p)$ & 20 & 25 & 30 & 35 & 40 \\
\hline Quantity $(q)$ & 80 & 70 & 60 & 50 & 40 \\
\hline Revenue $(R)$ & 1600 & 1750 & 1800 & 1750 & 1600 \\
\hline$E(p)$ & 0.5 & 0.71 & 1 & 1.4 & 2 \\
\hline
\end{tabular}

Source: own elaboration. 
It is worth noting that when the price elasticity of demand is greater than 1 , the increase of revenue from sales requires a decrease of the price. The price elasticity of supply is defined similarly.

Generally, the expression $E_{x} f\left(x_{0}\right)=\frac{f^{\prime}\left(x_{0}\right)}{f\left(x_{0}\right)} x_{0}$ is called the elasticity of function $f(x)$ with respect to $x$ at point $x_{0}$, that approximates a percentage change in the value of $f(x)$ following the increase of $x$ at point $x_{0}$ by $1 \%$.

\section{Problems for students:}

1. Given the demand function $q(p)=96-4 p$, find the price elasticity of demand at $p=15$, and propose an increase of the price by $10 \%$ to get an increased revenue; find the price that will maximize the revenue.

2. Evaluate the elasticity of: a linear function $f_{1}(x)=a x+b$, a rational function $f_{1}(x)=a x+b$, a power function $f_{3}(x)=a x^{a}$.

In order to illustrate the application of the formula evaluating the derivative of a composite function we can use the chain rule known in microeconomics. Assume a firm wants to increase its employment. We ask a question about the impact of this decision on the firm's revenue. Thus, we need to evaluate the derivative of the revenue function with respect to labour. The revenue depends on the quantity of production $q$, whereas production depends on labour input $L$. Let $R=f(q), q=g(L)$, then $R(L)=f[g(L)]$ and $\frac{d R}{d L}=\frac{d R}{d q} \frac{d q}{d L}$. This rule is interpreted by economists as: the marginal revenue with respect to labour equals the product of the marginal revenue with respect to sales and the marginal physical labour productivity.

The above-mentioned microeconomic examples should be generalized to functions of $n$ variables (two variables), thus the mathematical tools presented in lectures prove worthwhile.

\section{Derivative of functions of two variables; its economic interpretation}

Assume a consumer with the cardinal utility function $u: R_{+}{ }^{2} \rightarrow R$ and a basket of goods $\left(x_{1}, x_{2}\right)$ received a little of the good 1 equal to the quantity $\Delta x_{1}$. How did this change affect the consumer's utility? The rate of this change is called the marginal utility of good 1 and is expressed as:

$$
M U_{1}=\lim _{\Delta x_{1} \rightarrow 0} \frac{\Delta U}{\Delta x_{1}}=\lim _{\Delta x_{1} \rightarrow 0} \frac{u\left(x_{1}+\Delta x_{1}, x_{2}\right)-u\left(x_{1}, x_{2}\right)}{\Delta x_{1}}=\frac{\partial u\left(x_{1}, x_{2}\right)}{\partial x_{1}} .
$$


The marginal utility of good 2 is defined similarly, as a partial derivative of the utility function with respect to $x_{2}$. It is worthwhile drawing students' attention when we evaluate the marginal utility of good 1 (the partial derivative of the variable $x_{1}$ ), then the other good is at the invariable level ( $x_{2}$ is treated as a constant).

Analogously to a function of one variable we define the elasticity of function (of demand) with respect to each variable separately. Formula 5 presents the utility elasticity of the basket of goods with respect to the $i^{\text {th }}$ good, which reveals the percentage change of the basket utility following the increase of the $i^{\text {th }}$ good by $1 \%$, with the other good unchanged.

$$
E_{i}\left(x_{1}, x_{2}\right)=\lim _{\Delta x_{i} \rightarrow 0} \frac{u\left(x_{i}+\Delta x_{i}, x_{j}\right)-u\left(x_{i}, x_{j}\right)}{u\left(x_{i}, x_{j}\right)} \cdot \frac{x_{i}}{\Delta x_{i}}=\frac{\partial u\left(x_{1}, x_{2}\right)}{\partial x_{i}} \cdot \frac{x_{i}}{u\left(x_{i}, x_{j}\right)} .
$$

If we replace here $x_{i}$ by $p_{i}$ and $u$ by $q_{j}$, then we get the price elasticity of demand for the $j^{\text {th }}$ good with respect to the price of the $i^{\text {th }}$ good; we denote it by $E_{j i}\left(p_{1}, p_{2}, I\right)$, where $I$ denotes the amount of consumer's income spent for the purchase of both goods.

Microeconomic describes the preferences of consumers by indifference curves (contour lines of utility functions), i.e. the curves joining the baskets of the same utility. The gradient of the indifference curve (the slope of the tangent line) at a given point is known in economics as the marginal rate of substitution (MRS), as it measures the rate at which a consumer is willing to substitute one good by another. How can the utility function be utilized to evaluate the MRS? Let us consider such changes in the quantities of both goods in the basket $\left(\Delta x_{1}, \Delta x_{2}\right)$, that the basket does not move onto another indifference curve, i.e. the utility remains constant. By formula 4 we can write:

$$
0=\Delta U=\Delta U_{1}+\Delta U_{2}=M U_{1} \Delta x_{1}+M U_{2} \Delta x_{2} .
$$

Then $M R S=\frac{\Delta x_{2}}{\Delta x_{1}}=-\frac{M U_{1}}{M U_{2}}$ follows from (6).

Let us assume that a firm with employment $l$ produces two goods in quantities of $q_{1}$ and $q_{2}$, where $q_{1}=g_{1}(l), q_{2}=g_{2}(l)$. The goods are then used in production yielding the revenue $R=R\left(q_{1}, q_{2}\right)$. In order to evaluate profitability of the change in the level of workforce, we use the derivative of the composite function $R$, known in economics as the chain rule:

$$
\frac{d R}{d l}=\frac{\partial R}{\partial q_{1}} \frac{d q_{1}}{d l}+\frac{\partial R}{\partial q_{2}} \frac{d q_{2}}{d l} .
$$


Let us replace the function $R$ by the function $f(x)=F(x, g(x))$, then the chain rule can be expressed as:

$$
\frac{d f}{d x}=\frac{\partial F}{\partial x} \frac{d x}{d x}+\frac{\partial F}{\partial y} \frac{d y}{d x}=\frac{\partial F}{\partial x}+\frac{\partial F}{\partial y} \frac{d y}{d x} .
$$

Formulas 7 and 8 use the Greek delta $\partial f$ to denote the derivative of the function $f$ of two variables, whereas $d f$ denotes the derivative of the function of one variable.

Let us now apply formula 8 to the consumer's utility function $u(x, y)$. Then we get a relationship between the MRS and marginal utilities introduced above.

$$
0=d u=\frac{\partial u}{\partial x}+\frac{\partial u}{\partial y} \frac{d y}{d x} \Rightarrow \frac{d y}{d x}=-\frac{\frac{\partial u}{\partial x}}{\frac{\partial u}{\partial y}}=-\frac{M U_{1}}{M U_{2}}=M R S .
$$

The last example is about the maximization of the utility function $u\left(x_{1}, x_{2}\right)$, subject to a financial constraint $p_{1} x_{1}+p_{2} x_{2}=m$. Let us assume that a consumer can expend PLN70 to purchase two goods priced at PLN1 and PLN2, respectively. The consumer's utility function as regards $x$ units of the good 1 and $y$ units of the good 2 is given by the formula $u(x, y)=12 x^{\frac{1}{4}} y^{\frac{1}{3}}$. Find a basket of goods with maximum utility.

Mathematically we deal here with a constrained maximization problem that is solved by means of Lagrange multipliers. First, we define the Lagrangian:

$$
L(x, y, \lambda)=u(x, y)+\lambda\left(p_{1} x+p_{2} y-m\right)=12 x^{\frac{1}{4}} y^{\frac{1}{3}}+\lambda(x+2 y-70)
$$

and then, in order to find stationary points, we evaluate all partial derivatives of the Lagrange function and equate them to zero:

$$
\begin{gathered}
L_{x}^{\prime}(x, y, \lambda)=12 \cdot \frac{1}{4} x^{-\frac{3}{4}} y^{\frac{1}{3}}+\lambda=0, \\
L_{y}^{\prime}(x, y, \lambda)=12 \cdot \frac{1}{3} x^{\frac{1}{4}} y^{-\frac{2}{3}}+2 \lambda=0, \\
L_{\lambda}^{\prime}(x, y, \lambda)=x+2 y-70=0 .
\end{gathered}
$$

Since our consumer's indifference curves (the isoquants of the Cobb-Douglas function) are convex, we get the solution to this system of equations $x=30, y=20$, i.e. the required basket of goods is $(30,20)$. 


\section{Problems for students (continued):}

3. Capital $k$ and labour $l$ are used to produce $q$ units of a product, where $q=5 \cdot k^{\frac{2}{3}} l^{\frac{1}{3}}$. The unit cost of capital is PLN500 and the unit cost of labour is PLN100. Find the quantity of production to maximize revenue if the unit sales price of the product is PLN2000.

Note: $R(q)=2000 q-C(q)$.

\section{Conclusion}

The subject matter literature includes many books demonstrating applications of mathematics to microeconomics, especially publications by T. Bednarski, A. Ostoja-Ostaszewski and K. Malaga, which present microeconomic problems and exercises. Due to the shortage of time available to a mathematics course, and because of the varying students' capability, the lecturer is responsible for the appropriate choice of microeconomic examples. A good extension of microeconomic applications of calculus are macroeconomic examples, particularly regarding economic growth models, with the use of elements of differential equations. A number of such preliminary examples are presented in the paper by Biernacki [2015].

\section{Bibliography}

Bednarski T. (2004). Elementy matematyki w naukach ekonomicznych [Elements of Mathematics in Economic Sciences]. Oficyna Ekonomiczna.

Biernacki M. (2010). Applications of the integral in economics. A few simple examples for first-year students. Didactics of Mathematics 7 (11). Pp. 5-14.

Biernacki M. (2015) Elements of differential equations in the mathematics course for students of economics. Didactics of Mathematics 12 (16). Pp. 5-10.

Chiang A.C. (1994). Podstawy ekonomii matematycznej [Fundamental Methods of Mathematical Economics]. PWE. Warszawa.

Malaga K. (2010). Mikroekonomia. Oswajanie z matematyka [Microeconomics. Taming Mathematics]. C.H. Beck. Warszawa.

Ostoja-Ostaszewski A. (1996). Matematyka w ekonomii [Mathematics in Economics]. PWN. Warszawa.

Varian H. (1997). Mikroekonomia [Microeconomic Analysis]. PWN. Warszawa.

Żylicz T. (2006). Should economics students be taught mathematics? coin.wne.uw.edu.pl/ tzylicz/matekon.pdf. 